\title{
Investigation of In-48Sn as a phase change material candidate for thermal storage applications
}

\author{
Ashmore Mawire ${ }^{1, *}$ and Adedamola B. Shobo ${ }^{2}$ \\ ${ }^{1}$ Solar Thermal Energy Research Group, School of Mathematical and Physical Sciences, North-West University, Mafikeng, \\ South Africa \\ ${ }^{2}$ Department of Mathematics, Science and Sports Education, University of Namibia, Ongwendiva, Namibia
}

Received: 27 February 2017 / Received in final form: 4 July 2017 / Accepted: 27 July 2017

\begin{abstract}
Latent heat storage systems provide large thermal storage densities for solar energy storage for various domestic and industrial applications. In-48Sn, an alloy of indium and tin a lead-free solder is investigated as a phase change material (PCM) in latent heat storage systems for heating applications. Results obtained from differential scanning calorimetry indicate that the alloy is useful in storing sensible heat beyond its melting temperature as it exhibits very little decomposition up to $400^{\circ} \mathrm{C}$. Though $\mathrm{In}-48 \mathrm{Sn}$ possesses a low latent heat of fusion, its high density allows for a larger thermal storage mass. The behaviour of $\mathrm{In}-48 \mathrm{Sn}$ in a $50 \mathrm{~mm}$ aluminium spherical capsule during charging and discharging cycles is investigated using sunflower oil as the heat transfer fluid (HTF) at flow rates of 3 , 6,9 and $12 \mathrm{ml} / \mathrm{s}$. The influence of the charging temperature on the charging characteristics of the encapsulated PCM is also investigated. The average charging and discharging rates of the encapsulated PCM show an increase with an increase in the HTF flow rate. The HTF temperature determines the maximum temperature attained by the PCM and thus the total energy stored by the encapsulated PCM. In-48Sn shows good potential as a PCM in a spherical aluminium capsule for packed bed domestic heat storage systems.
\end{abstract}

\section{Introduction}

As part of efforts to lower carbon dioxide emissions with a view of reducing global warming, research activities have been geared towards harnessing renewable energy resources and supporting the use of sustainable energy resources. Thermal energy storage (TES) systems can be used to store thermal energy from time-dependent sources like solar radiation [1]. Latent heat thermal energy storage (LHTES) systems have found a great appeal due to the large thermal storage densities they possess and the quasi-isothermal behaviour of phase change materials (PCMs) during their phase transitions [2]. The melting/solidification temperatures of PCMs principally determine operational temperatures of the LHTES system in which they are utilized.

PCMs can be categorized into three classes: organic, inorganic and eutectics. Organic PCMs have been investigated extensively and found applications in the past years [3]. Paraffins are reported to possess high enthalpies of fusion, exhibit negligible supercooling, to be chemically inert and stable, exhibit no segregation and are reasonably priced. The down side to using paraffins as PCMs are their low thermal conductivity values and large volumetric expansion during melting [4]. Fatty acids have

\footnotetext{
* e-mail: ashmore.mawire@nwu.ac.za
}

been reported to also possess high enthalpies of fusion with very good melting and solidification characteristics without supercooling. However, fatty acids are expensive and slightly corrosive [5]. Low thermal conductivity values and supercooling are major issues linked with the use of sugar alcohols as PCMs [6]. Some salt hydrates have the attraction of high volumetric latent heats of fusion, higher thermal conductivity values than organic PCMs and low thermal expansion [5]. However, phase segregation and supercooling constitute major setbacks in the utilization of salt hydrates as PCMs. Eutetics, minimum-melting composition of any of: two organic PCMs, two inorganic compositions or an organic PCM and an inorganic PCM, have been reported to present congruent melting/solidification characteristics which are advantageous for thermal storage applications [4]. However, limited data is available on the thermophysical properties of eutectics.

Metals and metal alloys have been considered as PCMs because of their high thermal conductivity values, small volumetric expansion during phase change, large volumetric latent enthalpy of fusion and good stability after a lot of melting/solidification cycles [1,7]. However, few investigations and applications of metallic PCMs are found in literature. Akiyama et al. [8] studied the heat storage and release characteristics of some inorganic salts and metals for operational temperatures between 500 and $1100 \mathrm{~K}$. The 
(a)

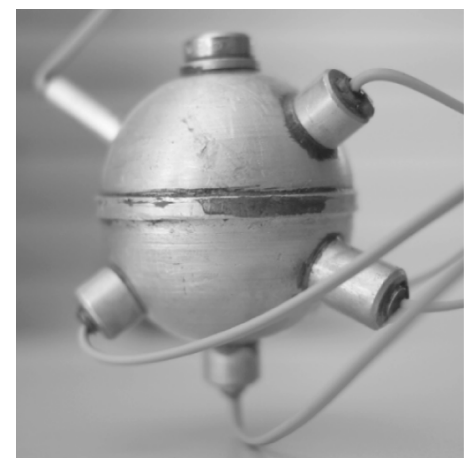

(b)

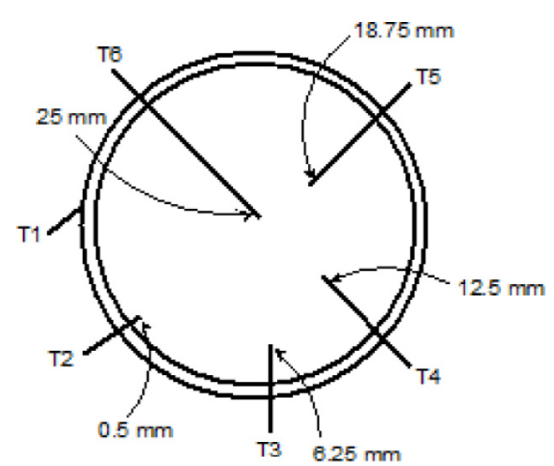

Fig. 1. (a) A photograph of the aluminium capsule. (b) A sketch of the cross-section of the aluminium capsule showing the positions of the thermocouples.

Table 1. Measured values of some thermophysical properties of the In-48Sn alloy.

\begin{tabular}{lllllll}
\hline Phase & $\begin{array}{l}\text { Density } \\
\left(\mathrm{kg} / \mathrm{m}^{3}\right)\end{array}$ & $\begin{array}{l}\text { Specific heat } \\
\text { capacity } \\
(\mathrm{J} / \mathrm{kg} \mathrm{K})\end{array}$ & $\begin{array}{l}\text { Thermal } \\
\text { diffusivity } \\
\left(\mathrm{m}^{2} / \mathrm{s}\right)\end{array}$ & $\begin{array}{l}\text { Thermal } \\
\text { conductivity } \\
(\mathrm{W} / \mathrm{m} \mathrm{K})\end{array}$ & $\begin{array}{l}\text { Melting } \\
\text { enthalpy } \\
(\mathrm{J} / \mathrm{kg})\end{array}$ & $\begin{array}{l}\text { Coefficient of } \\
\text { thermal expansion } \\
\left(\mathrm{K}^{-1}\right)\end{array}$ \\
\hline $\begin{array}{l}\text { Solid } \\
\left(30^{\circ} \mathrm{C}\right)\end{array}$ & 7290 & 233 & $24.05 \mathrm{E}-6$ & 40.851 & 24890 & $2.874 \mathrm{E}-5$ \\
$\begin{array}{l}\text { Liquid } \\
\left(120^{\circ} \mathrm{C}\right)\end{array}$ & 7220 & 416 & $20.43 \mathrm{E}-6$ & 61.362 & & $2.351 \mathrm{E}-5$ \\
\hline
\end{tabular}

study indicated that metallic PCMs gave better performance than inorganic salts for obtaining isothermal heat discharge due to their higher thermal conductivity values. Fukahori et al. [9] investigated aluminium-silicon alloys, with different silicon contents (0-25 wt\%), as PCMs. Risueño et al. [10] investigated two eutectic alloys: $\mathrm{Mg}_{70} \mathrm{Zn}_{24.9} \mathrm{Al}_{5.1}$ and $\mathrm{Zn}_{85.8} \mathrm{Al}_{8.2} \mathrm{Mg}_{6}$ as PCMs for TES in concentrated solar power (CSP) plants. Blanco-Rodriguez et al. [11,12] presented the characterization of $\mathrm{Mg}-51 \% \mathrm{Zn}$ as a $\mathrm{PCM}$ for TES in CSP plants. Adinberg et al. [13] presented the development and test reports of a TES system utilizing Zn70Sn30 as a PCM. Kotzé et al. [14] presented a conceptual design of a TES system designed for CSP plants, utilizing $\mathrm{AlSi}_{12}$ as a PCM. Nieto-Maestre et al. [15] presented a techno-economic evaluation of three novel metallic alloys: $\mathrm{Mg}(40-50 \%)-\mathrm{Zn}(40-50 \%)-\mathrm{Cu}(10-20 \%), \mathrm{Mg}(40-50 \%)-\mathrm{Zn}$ (40-50\%)- $\mathrm{Ni}(0-10 \%)$ and $\mathrm{Mg}(20-30 \%)-\mathrm{Zn}(40-50 \%)-\mathrm{Cu}$ (30-40\%) from a simulation study. Nomura et al. [16] presented a study of the microencapsulation of $\mathrm{Al}-25 \mathrm{wt} \% \mathrm{Si}$ for TES.

The few uses of metallic PCMs for TES for heating applications from literature as discussed above are focused on high-temperature (above $200{ }^{\circ} \mathrm{C}$ ) applications. There are limited studies which have investigated the use of metallic PCMs for low to medium temperature $\left(40-200{ }^{\circ} \mathrm{C}\right)$ heating applications. This study investigates the possibilities of utilizing In-48Sn as a PCM for medium-temperature heating applications. In-48Sn is an alloy comprising of $51.73 \%$ of indium and $48.27 \%$ of tin. It is commonly used as a lead-free solder for joining electronic components and it has been reported to have very low vapour pressure. The only application of this alloy as a PCM, found in literature, is for heat dissipation in an encapsulation for an electronic module in the invention of Myers et al. [17].

\section{Methodology}

A commercial grade ingot of In-48Sn alloy (purity 99\%) was purchased from The Indium Corporation of America, USA. The thermal diffusivity of a sample of the alloy was measured using NETZSCH laser flash apparatus LFA 467 HyperFlash ${ }^{\circledR}$ (accuracy: $\pm 3 \%$ ) at $30^{\circ} \mathrm{C}$ (solid phase) and at $120^{\circ} \mathrm{C}$ (liquid phase). An average of five measurements at each temperature was calculated. The specific heat capacity of the alloy was determined by using the NETZSCH DSC 204 F1 Phoenix ${ }^{\circledR}$ differential scanning calorimeter (accuracy: <2-3\%). The alloy sample was placed in a platinum crucible with an $\mathrm{Al}_{2} \mathrm{O}_{3}$ liner with a heating rate of $10^{\circ} \mathrm{C}$ in a dynamic nitrogen flow of $35 \mathrm{ml} /$ min. The thermal expansion of the sample was measured by using an NETZSCH DIL $402 \mathrm{C}$ pushrod dilatometer (accuracy: 0.003\%). The density and the coefficient of thermal expansion of the sample were determined from the thermal expansion data by a thermal analysis software. The thermal conductivity of the alloy was calculated at $30^{\circ} \mathrm{C}$ and at $120^{\circ} \mathrm{C}$ by using equation (1):

$$
\lambda=\rho^{*} c^{*} \alpha
$$

Thermal stability of the alloy was investigated by heating a sample of the alloy in an alumina pan, using the TA instrument's SDT Q600 differential scanning calorimeter at a rate of $10^{\circ} \mathrm{C} / \mathrm{min}$ from 50 to $400{ }^{\circ} \mathrm{C}$. The melting enthalpy was measured by using the TA instrument's SDT Q600 differential scanning calorimeter with a heating rate of $10^{\circ} \mathrm{C} / \mathrm{min}$ and under a constant nitrogen flow of $50 \mathrm{ml} /$ min. A $50 \mathrm{~mm}$ diameter sphere was fabricated from an aluminium alloy (1050-H14), filled with molten In-48Sn and then allowed to cool to room temperature under a flow 


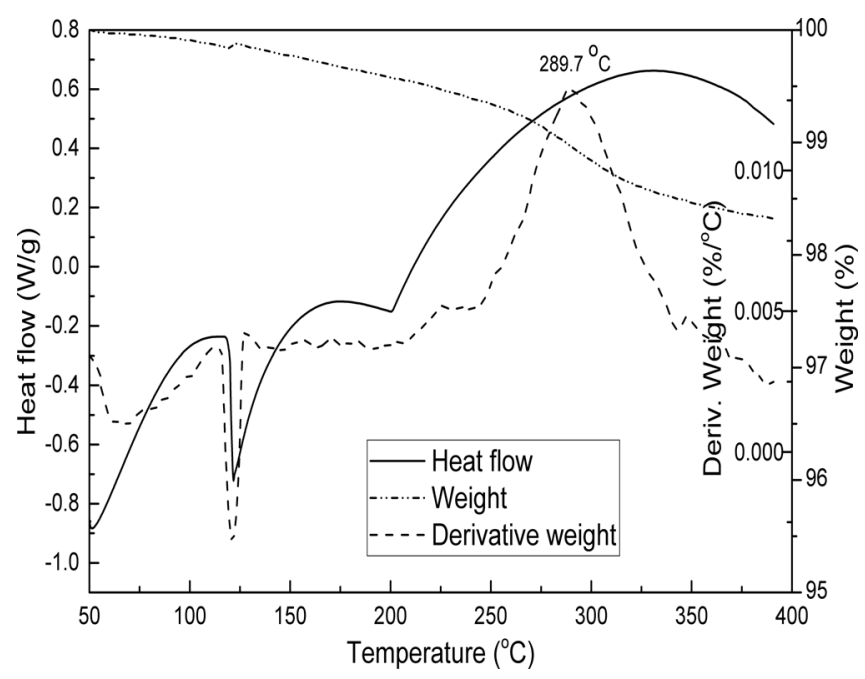

Fig. 2. The DSC/TGA thermogram of In-48Sn at a heating rate of $10^{\circ} \mathrm{C} / \mathrm{min}$.

of dry air. Figure $1 \mathrm{a}$ and $\mathrm{b}$ shows the photograph of the aluminium capsule and the positions of thermocouples, respectively. The K-type thermocouples were used to obtain the temperature of the capsule (T1) and the radial temperatures of the PCM (T2-T6). The sphere was then closed with a stainless steel screw cap and lowered into an insulated vertical cylinder filled with sunflower oil. The flow of sunflower oil into the vertical cylinder was controlled by a circulating pump and measured by a flow meter. The temperature of the heat transfer fluid (HTF) was controlled by presetting the maximum temperature of an electric heating unit through which the HTF flowed into the vertical cylinder. The temperature of the encapsulated PCM (EPCM) at any instant of time was taken as an average of the temperatures indicated by thermocouples T2, T3, T4, T5 and T6. The temperature data was recorded on a computer through a data acquisition unit every $10 \mathrm{~s}$.

The cumulative quantity of heat stored by the EPCM during charging $\left(Q_{c, \text { cum }}\right)$ was estimated by using equations $(2)-(4)$.

$$
\begin{gathered}
Q_{c, c u m}=m_{P C M} c_{S}\left(T_{a v}-T_{i n i}\right) ; \text { for } T_{a v}<T_{m 1} \\
Q_{c, c u m}=m_{P C M} c_{S}\left(T_{m 1}-T_{i n i}\right)+f m_{P C M} H+f m_{P C M} c_{L} \\
\left(T_{a v}-T_{m 1}\right) ; \text { for } T_{m 1}<T_{a v}<T_{m 2}, \\
Q_{c, c u m}=m_{P C M} c_{S}\left(T_{m 1}-T_{i n i}\right)+m_{P C M} H \\
+m_{P C M} c_{L}\left(T_{a v}-T_{m 2}\right) ; \quad T_{a v}>T_{m 2} .
\end{gathered}
$$

The cumulative energy discharged by the EPCM $\left(Q_{D, \text { cum }}\right)$ was estimated by equations $(5)-(7)$.

$$
\begin{gathered}
Q_{D, \text { cum }}=m_{P C M} c_{L}\left(T_{i n i}-T_{a v}\right) ; \text { for } T_{a v}>T_{m 2} \\
Q_{D, \text { cum }}=m_{P C M} c_{L}\left(T_{i n i}-T_{m 2}\right)+f m_{P C M} H+f m_{P C M} c_{S} \\
\left(T_{m 2}-T_{a v}\right) ; \quad \text { for } T_{m 2}>T_{a v}>T_{m 1},
\end{gathered}
$$

$$
\begin{gathered}
Q_{D, \text { cum }}=m_{P C M} c_{S}\left(T_{i n i}-T_{m 2}\right)+m_{P C M} H+m_{P C M} c_{L} \\
\left(T_{m 1}-T_{a v}\right) ; \text { for } T_{a v}<T_{m 1},
\end{gathered}
$$

where $m_{P C M}$ is the mass of the PCM in the capsule, $c_{P, S}$ and $c_{P, L}$ are the specific heat capacity of the PCM in the solid and liquid phases, respectively, $T_{i n i}$ is the initial average temperature of the PCM, $T_{a v}$ is the average temperature of the PCM, $f$ is the melt/solidification fraction of the PCM, $H$ is the latent heat of fusion, $T_{m 1}$ and $T_{m 2}$ are the melting onset and peak temperatures, respectively.

The average charging/discharging rates were calculated by:

$$
\begin{aligned}
& \text { Average charging or discharging rate } \\
& =\frac{\text { Total energy stored or released }(\mathrm{J})}{\text { Time taken }(\mathrm{s})}
\end{aligned}
$$

\section{Results and discussion}

\subsection{Thermal stability}

The alloy begins to show meaningful weight degradation at about $289.7^{\circ} \mathrm{C}$ as indicated by the peak noticed in the derivative weight curve in Figure 2.

\subsection{Thermophysical properties of In-48Sn in solid and liquid phases}

Table 1 shows the measured thermophysical properties of the In-48Sn at two temperatures $\left(30\right.$ and $\left.120^{\circ} \mathrm{C}\right)$ in order to understand the alloy's properties in both the solid and the liquid phases. The alloy showed a very small volume expansion of about $0.97 \%$ on melting. This will be advantageous for the encapsulation of this alloy as very little mechanical stress will be exerted on capsule walls. The specific heat capacity of the alloy increased in the liquid phase by almost $80 \%$ of its value in the solid phase. The alloy's sensible heat storage capacity thus increases by about $80 \%$ when it is in the liquid state. Thus, the stability of the alloy at temperatures well beyond its transition temperature is advantageous in storing higher temperature sensible heat. The thermal diffusivity of the alloy reduced on melting but it became more thermally conductive, by about $50 \%$. In-48Sn was observed to melt at about $118.63^{\circ} \mathrm{C}$ with a relatively low enthalpy of about $24890 \mathrm{~J} /$ $\mathrm{kg}$. Though this is low as compared to melting enthalpies of commonly used PCMs for heating applications, the large density of the alloy presents it with a large volumetric melting enthalpy of about $1.815 \times 10^{8} \mathrm{~J} / \mathrm{m}^{3}$.

\subsection{The influences of HTF flow rate on the charging and discharging performances of the encapsulated In-48Sn}

In-48Sn showed regular melting in the capsule at about $119^{\circ} \mathrm{C}$ at all the charging flow rates considered as observed in Figure 3a. It can be observed from Figure $3 a$ and $b$ that charging of the EPCM commenced faster at higher HTF flow rates with evident faster temperature response and thermal energy accumulation. The average charging rate for the 

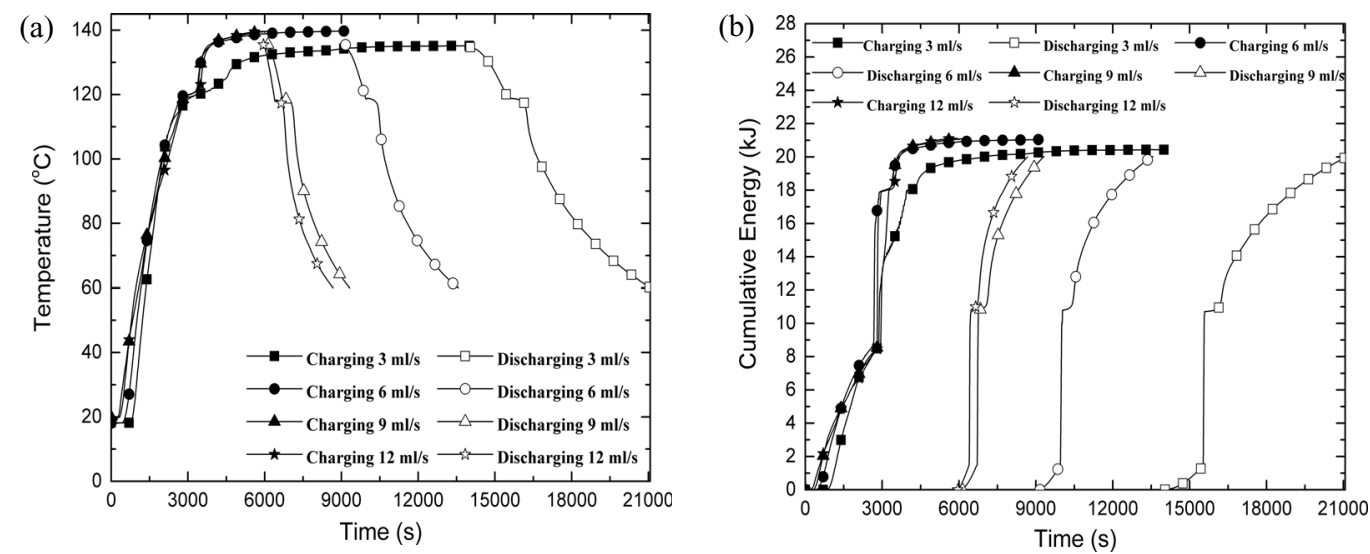

Fig. 3. (a) Average temperature histories of the EPCM during charging and discharging with the maximum heater temperature set at $150^{\circ} \mathrm{C}$ at different HTF flow rates. (b) The cumulative thermal energy stored and discharged by the EPCM during charging and discharging at the different HTF flow rates.
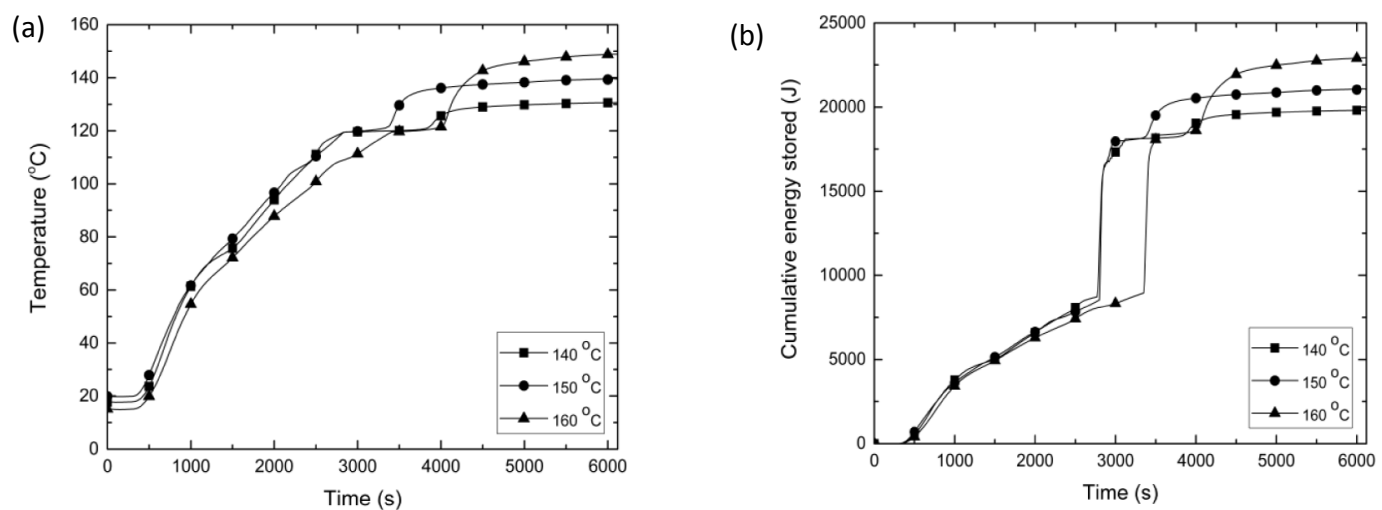

Fig. 4. (a) Average temperature histories of the EPCM and (b) the cumulative thermal energy stored by the EPCM while charging at with maximum HTF inlet temperature set at 140,150 and $160{ }^{\circ} \mathrm{C}$ with $\mathrm{HTF}$ flow rate of $9 \mathrm{ml} / \mathrm{s}$.

EPCM was $1.46 \mathrm{~J} / \mathrm{s}$ for the HTF flow rate of $3 \mathrm{ml} / \mathrm{s}, 2.30 \mathrm{~J} / \mathrm{s}$ for $6 \mathrm{ml} / \mathrm{s}, 3.44 \mathrm{~J} / \mathrm{s}$ for $9 \mathrm{ml} / \mathrm{s}$ and $3.56 \mathrm{~J} / \mathrm{s}$ for $12 \mathrm{ml} / \mathrm{s}$. The average charging rate increased with an increase in the HTF flow rate as expected. The temperature of the EPCM while charging at $3 \mathrm{ml} / \mathrm{s}$ never got to the expected $140^{\circ} \mathrm{C}$ as was obtained at the other flow rates, even after allowing it to continue charging for a longer time. The low charging flow rate resulted in more thermal losses from the EPCM and from the cylinder walls. The average discharging rate also increased with the HTF flow rate. It was $2.84 \mathrm{~J} / \mathrm{s}$ at $3 \mathrm{ml} /$ $\mathrm{s}, 4.54 \mathrm{~J} / \mathrm{s}$ at $6 \mathrm{ml} / \mathrm{s}, 6.28 \mathrm{~J} / \mathrm{s}$ at $9 \mathrm{ml} / \mathrm{s}$ and $7.35 \mathrm{~J} / \mathrm{s}$ at $12 \mathrm{ml} /$ $\mathrm{s}$. The alloy exhibited regular solidification at about $118.3^{\circ} \mathrm{C}$ at all the flow rates as can be observed in Figure 3b. The encapsulated In-48Sn alloy thus exhibits almost congruent melting and solidification characteristics with a degree of supercooling of about $0.7^{\circ} \mathrm{C}$.

\subsection{The influence of the HTF temperature on the charging performance of the encapsulated In-48Sn}

The influence of the charging temperature of the HTF was investigated by charging the EPCM at the same flow rate of $9 \mathrm{ml} / \mathrm{s}$ and at the same charging time of $6120 \mathrm{~s}$ as shown in Figure 4 . The set maximum heater temperatures for the charging tests were 140,150 and $160^{\circ} \mathrm{C}$. The temperature attained by the EPCM was clearly defined by the charging temperature as heat exchange between the HTF and the EPCM also depends on the temperature gradient between them. The average charging rate with maximum heater temperature at $140^{\circ} \mathrm{C}$ was $3.24 \mathrm{~J} / \mathrm{s}, 3.44 \mathrm{~J} / \mathrm{s}$ at $150^{\circ} \mathrm{C}$ and $3.75 \mathrm{~J} / \mathrm{s}$ at $160^{\circ} \mathrm{C}$. Thus, for efficient charging of the encapsulated In-48Sn alloy, a high HTF flow rate and the highest possible HTF charging temperature (lower than $289.7^{\circ} \mathrm{C}$ ) are essential.

\section{Conclusions}

In-48Sn was investigated as a PCM candidate for TES. In-48Sn showed great potential as a PCM that may be used in TES systems for medium temperature heating applications. The high thermal stability (to about $289.7^{\circ} \mathrm{C}$ ) shown by the alloy is advantageous in storing sensible heat at temperatures above its melting temperature. The low enthalpy of transition of the alloy was compensated for by its high density which presented it with a large volumetric melting enthalpy of about $1.815 \times 10^{8} \mathrm{~J} / \mathrm{m}^{3}$. The charging and discharging characteristics of In-48Sn inside a $50 \mathrm{~mm}$ diameter aluminium 
spherical capsule were also investigated. The alloy showed almost congruent melting and solidification characteristics with very small supercooling. The charging rates of the encapsulated alloy increased with an increase in the flow rate and with an increase in the temperature of the HTF. The discharging rate of the EPCM also increased with an increase in the flow rate of the HTF during discharging. In-48Sn is a promising PCM that can be used in packed bed TES systems for medium temperature heating applications.

\section{Nomenclature}

$c \quad$ specific heat capacity $(\mathrm{J} / \mathrm{kg} \mathrm{K})$

$c_{L} \quad$ specific heat capacity of liquid PCM $(\mathrm{J} / \mathrm{kg} \mathrm{K})$

$c_{S} \quad$ specific heat capacity of solid PCM $(\mathrm{J} / \mathrm{kg} \mathrm{K})$

$f \quad$ liquid/solid fraction in PCM sample $(-)$

$H \quad$ melting/solidification enthalpy $(\mathrm{J} / \mathrm{kg})$

$m_{p c m} \quad$ mass of PCM in capsule $(\mathrm{kg})$

$Q_{c, \text { cum }}$ cumulative thermal energy stored during charging (J)

$Q_{D, \text { cum }}$ cumulative thermal energy stored during discharging $(\mathrm{J})$

$T_{a v} \quad$ average radial temperature of PCM (K)

$T_{i n i} \quad$ initial average radial temperature of PCM (K)

$T_{m 1} \quad$ melting onset temperature $(\mathrm{K})$

$T_{m 2} \quad$ melting peak temperature $(\mathrm{K})$

$\alpha \quad$ thermal diffusivity of $\mathrm{PCM}\left(\mathrm{m}^{2} / \mathrm{s}\right)$

$\lambda \quad$ thermal conductivity of PCM $(\mathrm{W} / \mathrm{m} \mathrm{K})$

$\rho \quad$ density of PCM $\left(\mathrm{kg} / \mathrm{m}^{3}\right)$

\section{Abbreviations}

$\begin{array}{ll}\text { CSP } & \text { concentrated solar power } \\ \text { EPCM } & \text { encapsulated PCM } \\ \text { HTF } & \text { heat transfer fluid } \\ \text { LHTES } & \text { latent heat thermal energy storage system } \\ \text { PCM } & \text { phase change material }\end{array}$

The authors wish to acknowledge the support provided by the Material Science Innovation and Modeling (MaSIM) research focus area, Faculty of Agriculture, Science and Technology, Northwest University, South Africa. The authors also wish to acknowledge the National Research Foundation, South Africa, through the Research Development Grants for Y-rated Researchers (RDYR - Grant Number: 95574) and the Incentive Funding for Rated Researchers (IFRR - Grant Number: 90638) schemes.

\section{References}

1. R. Fukahori, T. Nomura, C. Zhu, N. Sheng, N. Okinaka, T. Akiyama, Macro-encapsulation of metallic phase change material using cylindrical-type ceramic containers for hightemperature thermal energy storage, Appl. Energy 170, 324 (2016)
2. Y. Tian, C.Y. Zhao, A review of solar collectors and thermal energy storage in solar thermal applications, Appl. Energy 104, $538(2013)$

3. M.M. Farid, A.M. Khudhair, S.A.K. Razack, S. Al-Hallaj, A review on phase change energy storage: materials and applications, Energy Convers. Manag. 45, 1597 (2004)

4. S.M. Hasnan, Review on sustainable thermal energy storage technologies, part I: heat storage materials and techniques, Energy Convers. Manag. 39, 1127 (1998)

5. A. Sharma, V.V. Tyagi, C.R. Chen, D. Buddhi, Review on thermal energy storage with phase change materials and applications, Renew. Sustain. Energy Rev. 13, 318 (2009)

6. M. Kenisarin, K. Mahkamov, Solar energy storage using phase change materials, Renew. Sustain. Energy Rev. 11, 1913 (2007)

7. H. Ge, H. Li, S. Mei, J. Liu, Low melting point metal as a new class of phase change material: an emerging frontier in energy area, Renew. Sustain. Energy Rev. 21, 331 (2013)

8. T. Akiyama, Y. Ashizawa, J. Yagi, Storage and release of heat in a single spherical capsule containing phase change material of high melting point, Trans. Jpn Soc. Mech. Eng. 57, 284 (1991)

9. R. Fukahori, T. Nomura, C. Zhu, N. Sheng, G. Saito, T. Akiyama, Thermal analysis of Al-Si alloys as high-temperature phase change materials and their corrosion properties with ceramic materials, Appl. Energy 163, 1 (2016)

10. E. Risueño, A. Faik, J. Rodriguez-Aseguinolaza, P. BlancoRodriguez, A. Gil, M. Tello, B. D'Aguanno, Mg-Zn-Al eutectic alloys as phase change material for latent heat thermal energy storage, Energy Proc. 69, 1006 (2015)

11. P. Blanco-Rodriguez, J. Rodriguez-Aseguinolaza, E. Risueño, M. Tello, Thermophysical characterization of $\mathrm{Mg}-51 \% \mathrm{Zn}$ eutectic metal alloy: a phase change material for thermal energy storage in direct steam generation applications, Energy 72, 414 (2014)

12. P. Blanco-Rodriguez, J. Rodriguez-Aseguinolaza, A. Gil, E. Risueño, B. D'Aguanno, I. Loroño, L. Martin, Experiments on a lab scale TES unit using eutectic metal alloy as PCM, Energy Proc. 69, 769 (2015)

13. R. Adinberg, D. Zvegilsky, M. Epstein, Heat transfer efficient thermal energy storage for steam generation, Energy Convers. Manag. 51, 9 (2010)

14. J.P. Kotzé, T.W. von Backström, P.J. Erens, High temperature thermal energy storage utilizing metallic phase change materials and metallic heat transfer fluids, ASME J. Solar Energy Eng. 135, 1 (2013)

15. J. Nieto-Maestre, I. Iparraguirre-Torres, Z.A. Velasco, I. Kaltzakorta, M.M. Zubieta, Novel metallic alloys as phase change materials for heat storage in direct steam generation applications, in Proceedings of the 21st SolarPACES International Conference (SolarPACES 2015), Capetown (2015)

16. T. Nomura, C. Zhu, N. Sheng, G. Saito, T. Akiyama, Microencapsulation of metal-based phase change material for high-temperature thermal energy storage, Scient. Rep. 5, 9117 (2015)

17. B. Myers, A. Chauhuri, J. Burns, Thermally-capacitive phase change encapsulant for electronic devices, Google Patents, US20030157342, http://www.google.is/patents/ US20030157342, 21 August 2003

Cite this article as: Ashmore Mawire, Adedamola B. Shobo, Investigation of In-48Sn as a phase change material candidate for thermal storage applications, Renew. Energy Environ. Sustain. 2, 20 (2017) 